EXTENDED REPORT

\title{
Patterns of cardiovascular risk in rheumatoid arthritis
}

\author{
D H Solomon, N J Goodson, J N Katz, M E Weinblatt, J Avorn, S Setoguchi, C Canning, \\ S Schneeweiss
}

See end of article for authors' affiliations

......................

Correspondence to: D H Solomon, Division of Pharmacoepidemiology, Brigham and Women's Hospital, 1620 Tremont Street, Suite 3030, Boston, MA 02120 , USA; dhsolomon@partners.org

Accepted 9 June 2006 Published Online First 22 June 2006
Background: Although it is known that rheumatoid arthritis is associated with an increased risk of cardiovascular disease (CVD), the pattern of this risk is not clear. This study investigated the relative risk of myocardial infarction, stroke and CVD mortality in adults with rheumatoid arthritis compared with adults without rheumatoid arthritis across age groups, sex and prior CVD event status.

Methods: We conducted a cohort study among all residents aged $\geqslant 18$ years residing in British Columbia between 1999 and 2003. Residents who had visited the doctor at least thrice for rheumatoid arthritis (International Classification of Disease $=714$ ) were considered to have rheumatoid arthritis. A nonrheumatoid arthritis cohort was matched to the rheumatoid arthritis cohort by age, sex and start of followup. The primary composite end point was a hospital admission for myocardial infarction, stroke or CVD mortality.

Results: 25385 adults who had at least three diagnoses for rheumatoid arthritis during the study period were identified. During the 5 -year study period, 375 patients with rheumatoid arthritis had a hospital admission for myocardial infarction, 363 had a hospitalisation for stroke, 437 died from cardiovascular causes and 1042 had one of these outcomes. The rate ratio for a CVD event in patients with rheumatoid arthritis was 1.6 (95\% confidence interval (Cl) 1.5 to 1.7), and the rate difference was $5.7(95 \% \mathrm{Cl} 4.9$ to 6.4) per 1000 person-years. The rate ratio decreased with age, from 3.3 in patients aged $18-39$ years to 1.6 in those aged $\geqslant 75$ years. However, the rate difference was 1.2 per 1000 person-years in the youngest age group and increased to 19.7 per 1000 person-years in those aged $\geqslant 75$ years. Among patients with a prior CVD event, the rate ratios and rate differences were not increased in rheumatoid arthritis.

Conclusions: This study confirms that rheumatoid arthritis is a risk factor for CVD events and shows that the rate ratio for CVD events among subjects with rheumatoid arthritis is highest in young adults and those without known prior CVD events. However, in absolute terms, the difference in event rates is highest in older adults.
$\mathrm{N}$ umerous studies have documented an increased burden of cardiovascular disease (CVD) in patients with rheumatoid arthritis. ${ }^{1-4}$ This risk may be modified by methotrexate and other drugs, ${ }^{5-7}$ and is associated with silent myocardial ischaemia. ${ }^{8}$ Traditional cardiovascular risk factors do not seem to account for this excess risk, ${ }^{9}$ but some studies suggest that patients with rheumatoid arthritis may have worse risk-factor profiles. $^{10}{ }^{11}$ There has not been agreement in the literature whether the risk is similar among men and women with rheumatoid arthritis. ${ }^{12-15}$ Relatively little information is available about the patterns of cardiovascular events across age groups, or cardiovascular disease status.

The aim of this study was to explore the distribution of CVD events in a large population with rheumatoid arthritis. We examined the rates for myocardial infarction, stroke and death from CVD in a population-based cohort of people with and without rheumatoid arthritis. Sex-specific and agespecific rate ratios as well as rate differences were calculated. We also assessed the risk for future events among subjects with and without prior cardiovascular events.

\section{METHODS}

\section{Study cohort}

The study population consisted of all people living in British Columbia, a Canadian province, and using its publicly funded healthcare system. All residents of this province receive a unique personal health number at birth and are entitled to all healthcare services provided in the province. The provincial government receives health insurance claims from all providers, including diagnosis and procedure codes associated with all inpatient and outpatient visits. All encounters in the Canadian healthcare system are recorded in this database. Previous studies of this database have shown a high degree of accuracy for many conditions, including arthritis and cardiovascular disease. ${ }^{16}$

For this study, we examined provincial healthcare data from 1999 to 2003 for people aged $\geqslant 18$ years. This data source lacks information on rheumatoid arthritis criteria, and thus a person was defined as having rheumatoid arthritis if they received three diagnoses (International Classification of Diseases-9-CM 714) over a period $\leqslant 2$ years. This definition is more stringent than other commonly used healthcare claimsbased definitions for rheumatoid arthritis. ${ }^{17}$ Follow-up started after the third diagnosis of rheumatoid arthritis during the study period (the index date) and continued until a patient sustained a CVD event, left the province or died (see below for definition of cardiovascular event). For each person defined as having rheumatoid arthritis, we attempted to select 10 people, matched with age, sex and index date without any diagnoses of rheumatoid arthritis who had visited a doctor thrice by their index date.

Data use agreements and approval from the relevant institutional review boards had been obtained.

Abbreviations: CVD, cardiovascular disease, ICD, International Classification of Disease 
Table 1 Cardiovascular events among subjects with and without rheumatoid arthritis, by age

\begin{tabular}{|c|c|c|c|c|c|c|c|c|c|c|}
\hline & \multicolumn{4}{|l|}{ RA } & \multicolumn{4}{|l|}{ No RA } & \multirow{2}{*}{$\begin{array}{l}\text { Rate difference } \\
(95 \% \mathrm{Cl})\end{array}$} & \multirow{2}{*}{$\begin{array}{l}\text { Rate ratio } \\
(95 \% \mathrm{Cl})\end{array}$} \\
\hline & n & Events & Person-years & Rate & $n$ & Events & Person-years & Rate & & \\
\hline All patients & 25385 & & & & 252976 & & & & & \\
\hline Ml & - & 375 & 71384 & 5.3 & - & 2022 & 709166 & 2.9 & $2.4(1.9-2.9)$ & $1.8(1.7-2.0)$ \\
\hline Stroke & - & 363 & 71260 & 5.1 & - & 1902 & 709489 & 2.7 & $2.4(2.0-2.9)$ & $1.9(1.7-2.1)$ \\
\hline CV death & - & 437 & 71912 & 6.1 & - & 3478 & 738212 & 4.7 & $1.4(0.9-1.9)$ & $1.3(1.2-1.4)$ \\
\hline $\begin{array}{l}\text { Any CV event } \\
\text { Age category } \\
\text { (Any CV event) }\end{array}$ & - & 1042 & 70612 & 14.8 & - & 6428 & 706059 & 9.1 & $5.7(4.9-6.4)$ & $1.6(1.5-1.7)$ \\
\hline $18-49$ & 6873 & 35 & 19900 & 1.8 & 68754 & 109 & 201873 & 0.5 & $1.2(0.7-1.7)$ & $3.3(2.4-4.5)$ \\
\hline $50-64$ & 8178 & 175 & 23473 & 7.5 & 80617 & 784 & 232648 & 3.4 & $4.1(3.1-5.0)$ & $2.2(1.9-2.5)$ \\
\hline $65-74$ & 5664 & 309 & 15735 & 19.6 & 56990 & 1617 & 159256 & 10.2 & $9.5(7.6-11.3)$ & $1.9(1.7-2.1)$ \\
\hline $75+$ & 4488 & 623 & 11414 & 54.6 & 46615 & 3918 & 112281 & 34.9 & $19.7(16.0-23.4)$ & $1.6(1.5-1.7)$ \\
\hline
\end{tabular}

CV, cardiovascular; MI, myocardial infarction; RA, rheumatoid arthritis.

The rate is events per 1000 person years. The rate difference is the absolute difference (excess) in events per 1000 people-years between patients with RA and those without RA. The composite outcome refers to MI, stroke or cardiovascular death.

\section{Cardiovascular events and risk factors}

The primary outcome was the first CVD event occurring during this study period, including hospitalisations for a myocardial infarction (ICD-9-CM codes 410 or 411 ) of at least 3 days unless the person died, ischaemic stroke (ICD-9CM 433 or 434) or death from CVD. These outcomes are accurately defined in healthcare utilisation databases, with a positive predictive value of $94 \%$ for myocardial infarction and $96 \%$ for stroke. ${ }^{18}{ }^{19}$ Death from CVD was defined on the basis of the cause of death diagnosis codes on death certificates, including out-of-hospital deaths. These codes included ICD9-CMs 410, 411, 414, 426, 427 and 430-438. Any cardiac cause coded on death certificates, when used broadly, is quite accurate on the basis of a prior study that used medical records as the criterion standard. ${ }^{20}$ The primary outcome was the composite of myocardial infarction, stroke or CVD death. In secondary analyses, we also examined the relative risk of 30-day mortality after myocardial infarction or stroke, comparing subjects with and without rheumatoid arthritis.

\section{Statistical analyses}

We summated the total person-years and the number of cardiovascular events in the populations with and without rheumatoid arthritis, and then calculated the rate per 1000 person-years with the corresponding 95\% confidence interval (CI). The rates were compared using two methods. Firstly, we calculated the absolute difference in rates per 1000 personyears between subjects with and without rheumatoid arthritis. Then, the rate ratio for the outcomes was calculated as the rate in rheumatoid arthritis divided by non-rheumatoid arthritis. These were calculated for the total study population, by strata of age, sex and prior CVD event status. Prior CVD events were defined by diagnosis codes for a previous myocardial infarction or stroke, or a hospital admission for myocardial infarction or stroke during the 24 months before the start of follow-up. Although we had $>24$ months of data for some members of the cohort, we did not have more information for all; thus, 24 months was chosen to ensure equal ascertainment of prior CVD. For the prior CVD event definition, we broadened the diagnostic algorithm to also include prior myocardial infarction (ICD 412). Calculations were performed using Episheet. ${ }^{21}$

\section{RESULTS}

We identified 25385 adults with at least three coded diagnoses of rheumatoid arthritis over a 2-year period from the provincial population that included 3.9 million people (http://www.bcstats.gov.bc.ca/data/cen0l/profiles/59000000.pdf.) The prevalence of rheumatoid arthritis among the study population was $0.65 \%$ from the healthcare utilisation data,

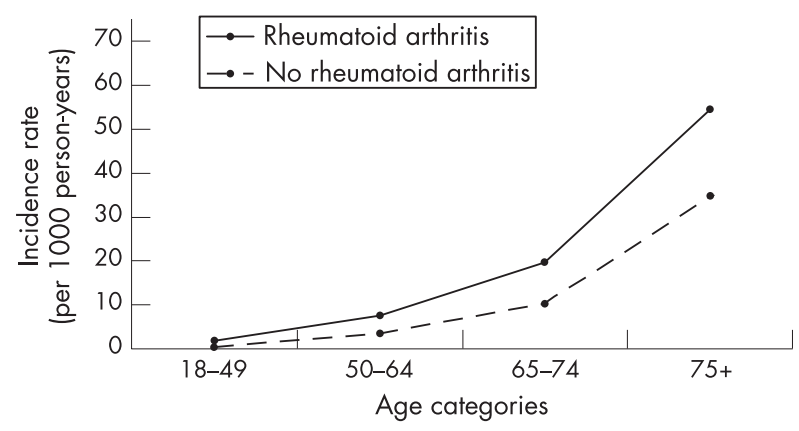

Figure 1 Incidence rates of cardiovascular events among the total study population.

similar to other population-based estimates based on clinical data. ${ }^{22}$ During the $>70,000$ years of follow-up for the rheumatoid arthritis cohort, 375 myocardial infarctions, 363 strokes and 437 CVD deaths were identified. Table 1 shows the rates for the composite outcome as well as myocardial infarction and stroke, which were higher for the patients with rheumatoid arthritis than those without. Patients with rheumatoid arthritis experienced an approximate doubling of risk for myocardial infarction and stroke and a 30\% increase in CVD death.

Similar calculations were carried out for subjects by age. As fig 1 shows, the rates were higher in patients with rheumatoid arthritis for all the age categories. The rate ratios were highest in the younger age groups (table 1), but the absolute difference in rates increased among the older age categories. Sex-specific analyses showed similar patterns (table 2).

Among subjects without prior CVD events, the pattern was similar to those for the total population (fig 2A). However, the pattern of risk was different for the patients with record of a prior CVD event (fig 2B). In this subgroup, rheumatoid arthritis was no longer associated with risk for future events; they seemed protected from future cardiovascular events in all age categories. To test whether this results was because of differential survival after a CVD event, we examined the risk of 30-day mortality for subjects with and without rheumatoid arthritis. The relative risk of 30-day mortality was increased for patients with rheumatoid arthritis, $(\mathrm{RR}=1.89,95 \% \mathrm{CI}$ 1.56 to 2.30 ).

\section{DISCUSSION}

We examined the rates, rate ratios and rate differences for myocardial infarction, stroke and CVD death in a populationbased cohort of subjects with and without rheumatoid 
Table 2 Cardiovascular event among subjects with and without rheumatoid arthritis, by age and sex

\begin{tabular}{|c|c|c|c|c|c|c|c|c|c|c|}
\hline & \multicolumn{4}{|l|}{ RA } & \multicolumn{4}{|l|}{ No RA } & \multirow[b]{2}{*}{$\begin{array}{l}\text { Rate difference }(95 \% \\
\mathrm{Cl})\end{array}$} & \multirow[b]{2}{*}{ Rate ratio $(95 \% \mathrm{Cl})$} \\
\hline & $\mathbf{n}$ & Events & $\begin{array}{l}\text { Person- } \\
\text { years }\end{array}$ & Rate & $\mathbf{n}$ & Events & Person-years & Rate & & \\
\hline \multicolumn{11}{|l|}{ Women } \\
\hline All ages & 18057 & 637 & 51055 & 12.4 & 180580 & 3948 & 510954 & 7.7 & 4.8 (3.9 to 5.6$)$ & $1.6(1.5$ to 1.7$)$ \\
\hline $18-49$ & 5012 & 19 & 14796 & 1.3 & 50189 & 50 & 150208 & 0.3 & $1.0(0.5$ to 1.4$)$ & $3.9(2.5$ to 6.0$)$ \\
\hline $50-64$ & 5756 & 94 & 16709 & 5.6 & 57269 & 348 & 165025 & 2.1 & $3.5(2.5$ to 4.5$)$ & $2.7(2.2$ to 3.2$)$ \\
\hline $65-74$ & 3854 & 166 & 10965 & 15.1 & 38845 & 861 & 111195 & 7.7 & 7.4 (5.4 to 9.4$)$ & $2.0(1.7$ to 2.2$)$ \\
\hline $75+$ & 3435 & 358 & 8584 & 41.7 & 34277 & 2689 & 84525 & 31.8 & $9.8(6.1$ to 13.7$)$ & $1.3(1.2$ to 1.4$)$ \\
\hline \multicolumn{11}{|l|}{ Men } \\
\hline All ages & 7328 & 405 & 19557 & 20.1 & 73296 & 2480 & 195105 & 12.7 & 8.0 (6.3 to 9.7$)$ & $1.6(1.5$ to 1.8$)$ \\
\hline $18-49$ & 1861 & 16 & 5193 & 3.1 & 18565 & 59 & 51665 & 1.1 & $1.9(0.6$ to 3.3$)$ & 2.7 (1.7 to 4.3$)$ \\
\hline $50-64$ & 2422 & 81 & 6763 & 12.0 & 23348 & 436 & 67622 & 6.4 & 5.5 (3.3 to 7.8$)$ & 1.9 (1.5 to 2.3$)$ \\
\hline $65-74$ & 1810 & 143 & 4770 & 30.0 & 18145 & 756 & 48061 & 15.7 & $14.2(9.0$ to 18.5$)$ & $1.9(1.7$ to 2.2$)$ \\
\hline $75+$ & 1235 & 165 & 2830 & 58.3 & 12338 & 1,229 & 27757 & 44.3 & 14.0 (6.3 to 21.8$)$ & $1.3(1.1$ to 1.5$)$ \\
\hline
\end{tabular}

MI, myocardial infarction; RA, rheumatoid arthritis.

The rate is events per 1000 person years. The rate difference is the absolute difference (excess) in events per 1000 person-years between patients with RA and those without RA. The composite outcome refers to MI, stroke or cardiovascular death.

arthritis. As has been described previously, we observed an approximate doubling of the rate of myocardial infarction and stroke in patients with rheumatoid arthritis. The rate of CVD death was increased by $30 \%$ in patients with rheumatoid arthritis. The rate ratios were similar for men and women. With increasing age, the rate ratios decreased, but the absolute rate differences increased. This pattern has been observed in other settings $\mathrm{s}^{23}$ and points out the important distinction between relative risk and absolute risk-even though relative risks of CVD may diminish with older age, the absolute risks grow because the overall risk of CVD increases with age.

No difference in age-adjusted CVD events was noted between sexes. This finding differs from that described in other studies, where the relative risk was higher in female than in male patients. ${ }^{12}{ }^{13}$ This apparent discrepancy in findings may be accounted for by the relatively small number of men with rheumatoid arthritis assessed in prior studies. Also, mechanisms specific to rheumatoid arthritis may override typical sex differences in CVD risk factors. We found an increased risk of stroke among patients with rheumatoid arthritis. Prior studies have not universally come to similar conclusions, ${ }^{1}$ but relatively small numbers of strokes were included in those studies. Also, the risk of 30-day mortality was higher for patients with rheumatoid arthritis than those without rheumatoid arthritis; this has been observed in at least one other study. ${ }^{4}$

The patterns of risk observed suggest several conclusions. On the one hand, the relative risks for cardiovascular events in patients with rheumatoid arthritis are highest for young patients and those without prior CVD events. However, as would be expected, the increase in absolute events is greatest among older patients. Such patients have the highest event rates and thus even small elevations in the rate ratio translate into large differences in absolute event rates. Also, this phenomenon underscores the concept of competing risks-as a population ages, a relatively uncommon risk factor for CVD (such as rheumatoid arthritis) becomes less influential relative to other risk factors.

Our data indicate a constant or slightly increasing number of excess cardiovascular events attributable to rheumatoid arthritis with increasing age. The relative increase in cases, calculated in this study as the rate ratio, becomes progressively smaller with increasing age. This pattern has been described before, ${ }^{24}$ and can be explained by the increasing risk attributable to age-that is, most patients are at an increasing risk for cardiovascular events with older age, and therefore the rate of events in subjects with and without rheumatoid arthritis increases with age. This increase in the cardiovascular event rate attributable to age is proportionally

Table 3 Any cardiovascular event among patients with rheumatoid arthritis, by age and prior cardiovascular event

\begin{tabular}{|c|c|c|c|c|c|c|c|c|c|c|}
\hline & \multicolumn{4}{|l|}{ RA } & \multicolumn{4}{|l|}{ No RA } & \multirow[b]{2}{*}{ Rate difference $(95 \% \mathrm{Cl})$} & \multirow[b]{2}{*}{ Rate ratio $(95 \% \mathrm{CI}$} \\
\hline & $\mathbf{n}$ & Events & $\begin{array}{l}\text { Person- } \\
\text { years }\end{array}$ & Rate & $\mathbf{n}$ & Events & $\begin{array}{l}\text { Person- } \\
\text { years }\end{array}$ & Rate & & \\
\hline \multicolumn{11}{|l|}{ No prior CV event } \\
\hline All ages & 24413 & 828 & 68525 & 12.1 & 248213 & 4700 & 697455 & 6.7 & $5.4(4.6$ to 6.1$)$ & 1.8 (1.7 to 1.9$)$ \\
\hline $18-49$ & 6824 & 29 & 19866 & 1.5 & 68596 & 68 & 201558 & 0.3 & $1.1(0.7$ to 1.6$)$ & 4.3 (3.0 to 6.2 ) \\
\hline $50-64$ & 7962 & 144 & 22921 & 6.2 & 79727 & 510 & 230778 & 2.2 & 4.1 (3.2 to 4.9$)$ & 2.8 (2.4 to 3.3$)$ \\
\hline $65-74$ & 5339 & 243 & 15017 & 16.2 & 55579 & 1139 & 156410 & 7.3 & $8.9(7.2$ to 10.0$)$ & $2.2(2.0$ to 2.5$)$ \\
\hline $75+$ & 4282 & 412 & 10722 & 38.4 & 44,311 & 2,983 & 108710 & 27.4 & 11.0 (7.8 to 14.2$)$ & $1.4(1.3$ to 1.5$)$ \\
\hline \multicolumn{11}{|l|}{$\begin{array}{l}\text { Any prior } \\
\text { cardiovascular event }\end{array}$} \\
\hline All ages & 972 & 214 & 2087 & 102.5 & 4763 & 1728 & 8604 & 200.8 & $-98.3(-112.3$ to -84.3$)$ & $0.5(0.5$ to 0.6$)$ \\
\hline $18-49$ & 49 & 6 & 124 & 48.5 & 158 & 41 & 315 & 130.3 & $-81.8(-128.4$ to -35.1$)$ & $0.4(0.2$ to 0.8$)$ \\
\hline $50-64$ & 216 & 31 & 552 & 56.2 & 890 & 274 & 1871 & 146.5 & $-90.3(-112.4$ to -68.2$)$ & $0.4(0.3$ to 0.5$)$ \\
\hline $65-74$ & 325 & 66 & 719 & 91.8 & 1,411 & 478 & 2847 & 167.9 & $-76.1(-98.6$ to -53.6$)$ & $0.5(0.4$ to 0.7$)$ \\
\hline $75+$ & 382 & 111 & 692 & 160.4 & 2304 & 935 & 3572 & 261.8 & $-101.4(-130.1$ to -72.6$)$ & $0.6(0.5$ to 0.7$)$ \\
\hline
\end{tabular}

Ml, myocardial infarction; RA, rheumatoid arthritis.

The rate is events per 1,000 person years. The rate difference is the absolute difference in events per 1000 person years between patients with RA and those without RA. The composite outcome refers to myocardial infarction, stroke, or cardiovascular death. Prior cardiovascular event refers to a diagnosis code for a myocardial infarction or stroke during the 24 months before start of follow-up. 

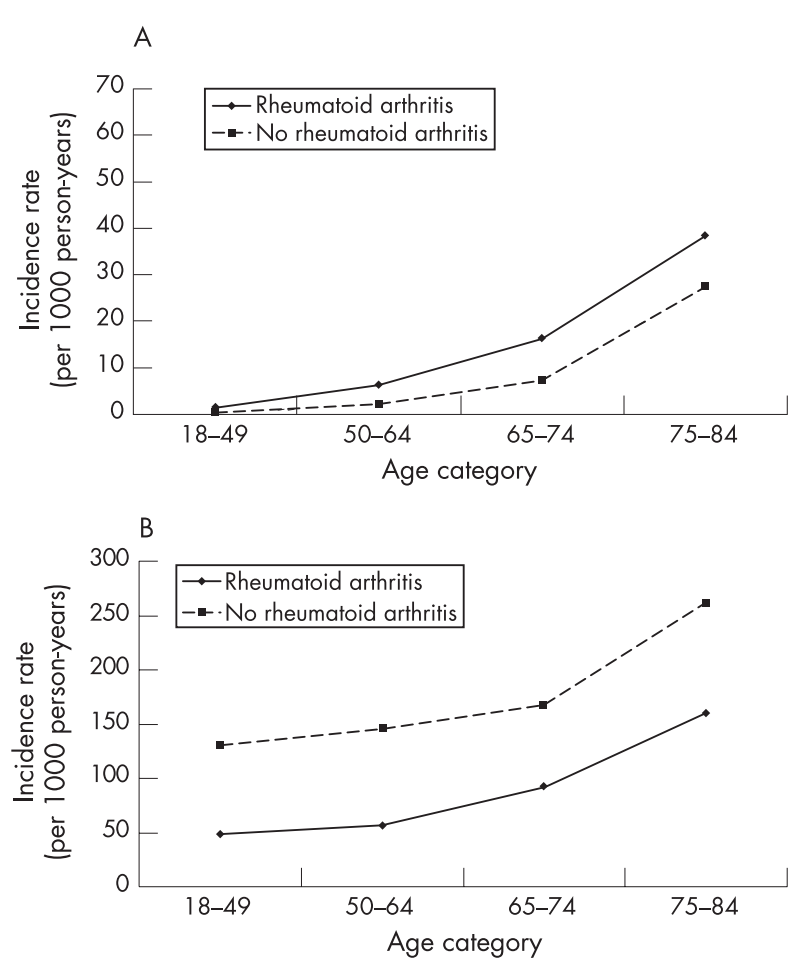

Figure 2 Incidence rates of cardiovascular events among subjects (A) with no prior event; (B) with prior event.

larger than the increase attributable to rheumatoid arthritis. Hence, the rate ratio assigned to rheumatoid arthritis seems smaller with increasing age. It would be incorrect to conclude from these data that the effect of rheumatoid arthritis on cardiovascular events diminishes with age. On the contrary, our data show a constant or increasing excess risk owing to rheumatoid arthritis with increasing age.

One unexpected finding was the lack of an increased risk of subsequent CVD events among patients with rheumatoid arthritis who had experienced a prior CVD event, as compared with those without rheumatoid arthritis who had experienced a prior CVD event. One potential explanation for this finding is that the patients with rheumatoid arthritis who survive a first event are healthier than those without rheumatoid arthritis who survive. This might produce a healthier cohort that has fewer second CVD events. This explanation is supported by our finding of higher risk of 30day mortality after a myocardial infarction or stroke for patients with rheumatoid arthritis. Another possibility is that unique risk factors may make patients with rheumatoid arthritis more likely than their counterparts without rheumatoid arthritis to experience incident CVD. But the factors associated with CVD in rheumatoid arthritis may not have a strong an influence on subsequent events. The difference may also be related to some aspect of the healthcare delivery system. Patients with rheumatoid arthritis may have greater access to the healthcare system because of their chronic disease and thus may receive relatively more secondary CVD prevention. Also, patients with severe CVD may be less likely to receive diagnoses of rheumatoid arthritis. Owing to this, the patients who do receive diagnoses of rheumatoid arthritis have had less severe CVD events. These subgroup findings warrant examination with a prospective cohort design.

Our study has several important limitations. We have no information about pre-clinical CVD and silent myocardial ischaemia would not be represented. Thus, our data may underestimate the rates and rate ratios associated with rheumatoid arthritis. Because our data only extend back 2 years before the start of follow-up ("left-censored" data), we have limited information on prior CVD and thus have been careful to not use the term "incident" when describing CVD events. Two-year baseline data were available for all patients, limiting the potential for bias. These analyses have not included information about exposure to drugs and other covariates, all possible modifiers of CVD risk. The database does not contain information about body mass index, tobacco use, aspirin use or other possible cardiovascular risk factors. Other studies have suggested that these issues are similarly distributed across women with and without rheumatoid arthritis. $\quad$ The algorithms for defining CVD events in healthcare utilisation data do not come from British Columbia. Finally, the diagnosis of rheumatoid arthritis is made on the basis of healthcare utilisation data and not the accepted American College of Rheumatology criteria. ${ }^{25}$ However, we have used a definition even more stringent than what others have used in healthcare claim analyses. By enhancing the stringency of the rheumatoid arthritis definition, we may have improved the specificity of the rheumatoid arthritis diagnosis, specificity being most critical for valid epidemiological studies. ${ }^{26}$ Our estimate of the prevalence of rheumatoid arthritis is also similar to that in other adult populations..$^{23}$ Hence, misclassification of rheumatoid arthritis would have introduced a conservative bias, such that the estimates would be closer to the null.

Can these results help inform policies for screening and treatment of patients with rheumatoid arthritis to prevent cardiovascular outcomes? The public health perspective teaches us to strive for the greatest good for the most people. Accordingly, there are strong reasons to target patients at highest absolute risk, such as older patients with rheumatoid arthritis. In addition, patients at the highest relative risk, younger patients and those without known cardiovascular disease may have the most to lose if we exclude them from prevention strategies. These analyses suggest that both young and old patients with rheumatoid arthritis are at an increased risk for cardiovascular outcomes and both groups should be included when considering preventive strategies.

\section{Authors' affiliations}

D H Solomon, N J Goodson, J N Katz, M E Weinblatt, J Avorn, S Setoguchi, C Canning, S Schneeweiss, Division of Pharmacoepidemiology, Brigham and Women's Hospital, Boston, Massachussetts, USA

Competing interests: None declared.

\section{REFERENCES}

1 Solomon DH, Karlson EW, Rimm EB, Cannuscio CC, Mandl LA, Manson JE, et al. Cardiovascular morbidity and mortality in patients with rheumatoid arthritis. Circulation 2003;107:1303-7.

2 Del Rincon I, Williams K, Stern MP, Freeman GL, O'Leary DH, Escalante A. Association between carotid atherosclerosis and markers of inflammation in rheumatoid arthritis patients and healthy subjects. Arthritis Rheum 2002;48: 1833-40.

3 Krishnan E, Lingala VB, Singh G. Declines in mortality from acute myocardial infarction in successive incidence and birth cohorts of patients with rheumatoid arthritis. Circulation 2004;110:1774-9.

4 Goodson NJ, Marks J, Lunt M, Symmons DPM. Cardiovascular admissions and mortality in an inception cohort of patients with rheumatoid arthritis with an onset in the 1980's and 1990's. Ann Rheum Dis 2005;64:1595-601.

5 Choi HK, Hernan MA, Seeger JD, Robins JM, Wolfe F. Methotrexate and mortality in patients with rheumatoid arthritis: a prospective study. Lancet 2002;359:1173-7.

6 Wei L, MacDonald TM, Walker BR. Taking glucocorticoids by prescription is associated with subsequent cardiovascular disease. Ann Intern Med 2004; 141:764-70.

7 Gonzalez-Juanatey C, Testa A, Garcia-Castelo A, Garcia-Porrua C, Llorca J, Gonzalez-Gay MA. Active but transient improvement of endothelial function in rheumatoid arthritis patients undergoing long-term treatment with antitumor necrosis factor alpha antibody. Arthritis Rheum 2004;51:447-50. 
8 Maradit-Kremers H, Crowson CS, Nicola PJ, Ballman KV, Roger VL, Jacobsen SJ, et al. Increased unrecognized coronary heart disease and sudden deaths in rheumatoid arthritis: a population-based cohort study. Arthritis Rheum 2005;52:402-11.

9 Solomon DH, Curhan GC, Rimm EB, Cannuscio CC, Karlson EW. Cardiovascular risk factors in women with and without rheumatoid arthritis. Arthritis Rheum 2004;50:3444-9.

10 Park YB, Lee SK, Lee WK, Suh CH, Lee CW, Lee CH, et al. Lipid profiles in untreated patients with rheumatoid arthritis. J Rheumatol 1999:26:1701-4.

11 Heliövaara M, Aho K, Knekt P, Reunanen A, Aromaa A. Serum cholestero and risk of rheumatoid arthritis in a cohort of 52800 men and women. Br J Rheumatol 1996;35:255-7.

12 Allebeck P. Increased mortality in rheumatoid arthritis. Scand J Rheumatol 1982;11:81-6.

13 Kvalvik AG, Jones MA, Symmons DPM. Mortality in a cohort of Norwegian patients with rheumatoid arthritis followed from 1977 to 1992. Scand J Rheumatol 2000;29:29-37.

14 Biornadal L, Baecklund E, Yin L, Granath F, Klareskog L, Ekbom A. Decreasing mortality in patients with rheumatoid arthritis: results from a large population based cohort in Sweden, 1964-95. J Rheumato 2002;29:906-12.

15 Turesson C, Jarenros A, Jacobsson L. Increased incidence of cardiovascular disease in patients with rheumatoid arthritis: results from a community based study. Ann Rheum Dis 2004;63:952-5.

16 Williams JI, Young W. Inventory of studies on the accuracy of Canadian health administrative databases, Technical report, Institute for Clinical Evaluative Sciences (ICES), December, 1996.
17 MacLean $\mathrm{CH}$, Louie R, Leake B, McCaffrey DF, Paulus HE, Brook RH, et al. Quality of care for patients with rheumatoid arthritis. JAMA 2000;284:984-92

18 Kiyota Y, Schneeweiss S, Glynn RJ, Cannuscio CC, Avorn J, Solomon DH. Accuracy of Medicare claims-based diagnosis of acute myocardial infarction: estimating positive predictive value on the basis of review of hospital records. Am Heart J 2004; 148:99-104.

19 Birman-Deych E, Waterman AD, Yan Y, Nilasena DS, Radford MJ, Gage BF Accuracy of ICD-9-CM codes for identifying cardiovascular and stroke risk factors. Med Care 2005;43:480-5.

20 Sesso HD, Gaziano JM, Glynn RJ, Buring JE. Value of an endpoints committee versus the use of nosologists for validating cause of death. Contemp Clin Trials 2006;27:333-9.

21 Rothman KJ. Episheet; spreadsheets for the analysis of epidemiologic data. http://members.aol.com/krothman/episheet.xls (accessed 16 Oct 2006).

22 Gabriel SE. The epidemiology of rheumatoid arthritis. Rheum Dis Clin North Am 2001;27:269-81.

23 Rothman KJ, Poole C. A strengthening programme for weak associations. Int J Epidemiol 1988; 17:955-9.

24 Garcia Rodriguez LA, Hernandez-Diaz S. Risk of uncomplicated peptic ulcer among users of aspirin and nonaspirin nonsteroidal antiinflammatory drugs. Am J Epidemiol 2004;159:23-31.

25 Arnett FC, Edworthy SM, Bloch DA, et al. The American Rheumatism Association 1987 revised criteria for the classification of rheumatoid arthritis. Arthritis Rheum 1988;31:315-24.

26 Kelsey JL, Whittemore AS, Evans AS, Thompson WD. Methods in observational epidemiology. New York: Oxford University Press, 1996. 